to portray a situation of scientific interest may be seen in No. 167, entitled "The Wilson Observer, 1933", by Winifred M. Abram. The portrait of Sir Almroth Wright (26) by Mr. Gerald F. Kelly exhibits a quality which will please all who are satisfied with photographic accuracy. Other portraits likely to interest readers of NATURE are those of Major C. H. Douglas, consulting engineer and economist (3), by Mr. Augustus E. John, R.A.; Prof. H. M. Macdonald, professor of mathematics in the University of Aberdeen (254), by Mr. R. G. Eves; Sir George Buckston Browne (1096), a miniature by Mr. P. Buckman. Since the portraits exhibited at the Academy are often of especial interest, a small additional index to them might with advantage be included in the catalogue.
The work of Mr. Terrick Williams, R.A., entitled "Sun and Mist, Mousehole" (19), is interesting as representing some beautiful changes in appearances due to the dispersion of light through an atmosphere laden with warm vapour.

One outstanding feature of this year's exhibition is the large scale model ( 1 in. to $4 \mathrm{ft}$.) of the Metropolitan Cathedral of Liverpool, made by Mr. John B. Thorp, to the designs of Sir Edwin Lutyens, R.A. Finally, we may direct attention to the remarkable metallic sheen upon the herald's coat in the portrait of Sir Gerald Wollaston, Garter Principal King of Arms (237), by Mr. Harold Knight. The brilliant lustre of polished gold is perfectly imitated, merely by the skilful use of suitable pigments.

\title{
Dr. Boys on Gas Calorimetry
}

THE nineteenth Guthrie lecture of the Physical Society was delivered on May 4 by Dr. C. V. Boys, one of the Gas Referees, who took as his subject "My Recent Progress in Gas Calorimetry". Lord Rayleigh presided.

After referring to his very close association with Prof. Guthrie, Dr. Boys remarked that "the making of specious scientific surmises unsupported by experiment, however amusing it may be as a pastime or however loudly it may be advertised, does nothing to advance the certain knowledge of the world ; the acid test of experiment is essential. So will you, who in years to come will have the management of this Society in your hands, accept this as a solemn message from the dead. If you would be true to the ideals of Guthrie, you will seek for a Guthrie lecturer from among those who have done things rather than from those who have merely talked."

Proceeding, Dr. Boys stated that he had not been entirely satisfied with the gas calorimeters he had already invented, but now, as the result of work extending over the last nine years, he had designed a calorimeter which gave him complete satisfaction. The essentials of a water-flow calorimeter for measuring the heating value of gas comprise a stream of water to be heated by the combustion of a supply of gas, and means for indicating or recording the resulting rise of temperature of the water stream. As the volume of a given mass of gas depends on its temperature and pressure, it is clear that means must be provided either to correct such volume to standard conditions of temperature and pressure, or alternatively to ensure that water shall flow through the calorimeter at a rate proportional to the uncorrected density of the gas, that is, inversely proportional to the volume at the time of a standard volume of gas.

In his previous recording calorimeter, Dr. Boys utilised the first of these alternatives ; in the present instrument (Fig. 1) the latter alternative is adopted. The appropriate hyperbolic relation is realised practically by a device which ensures that the depth of water in the vessel $A$ is proportional to the density of the gas, and that water is picked up from this vessel and delivered to the calorimeter $F$ in this same proportion. The device comprises (1) the closed burette tube, $D$, containing air or other gas, carried on the radial arm, $C$, and immersed at its lower open end in a vessel containing mercury, (2) four rotating scoops carried on arms for collecting distilled water from the lower vessel $B$ and delivering it to the upper vessel, $A$; these pick up rather more than is required for the calorimeter water; (3) a pair of rotating scoops and delivery vessels, of which one is shown at $E$, for collecting the appropriate volume of water from $A$ and delivering same to the calorimeter proper, $F$. The excess of water escapes from a siphon carried by the arm $C$, thus maintaining the required level. The motive power for driving the mechanism is derived via a 'Meccano' chain from the small electric motor shown at $H$. The water flow system requires the addition of only about 1 gallon of water per annum to replace that lost by evaporation.

The gas-pump, $G$, for supplying gas to the calorimeter, incorporates a number of novel features. Hitherto, the calorific value of gas supplied for towns' use has been measured with reference to a volume of gas saturated with water vapour, at atmospheric temperature. Within recent years, there has been an increasing tendency on the part of gas companies to supply dried gas, that is, gas from which a very considerable proportion of the water vapour ordinarily present has been removed. In order that the calorific value of such, or any other, gas shall be measured with reference to its actual water vapour content, whether saturated or unsaturated, the gas pump, $G$, uses mercury as confining liquid. Briefly, the pump comprises an inner cylinder having six longitudinal compartments accurately reamed out, and rotating within an outer casing. Appropriate inlet and outlet ports are provided for each compartment. The same 
small electric motor, $H$, driving the water supply device, rotates the inner drum of the gas pump and causes gas to be delivered to the calorimeter proper, $F$, at a constant rate of $\frac{1}{2}$ cub. ft. of gas per hour. The volume of gas is accurately determined from the known dimensions of the pump. Water levelling, which is an essential and troublesome operation with all existing forms of wet meter in order that the gas volume may be accurately known, is no longer necessary.

The calorimeter,

$F$, is of very small thermal capacity, so that a reading of outlet water temperature, steady to within about $0.01^{\circ}$ $\mathrm{C}$., is attained in about 15 minutes; and this despite the fact that with the calorimeter as at present constructed, the flow of water through the calorimeter is intermittent in character. Later, if found preferable, the water flow will be made continuous. $\mathrm{Th}$ e gas burns at the end of a small tube made of Pyrex glass which is carried by the arrangement including a Watt parallel motion device shown at $J$. The tubes of this parallel motion device can be used

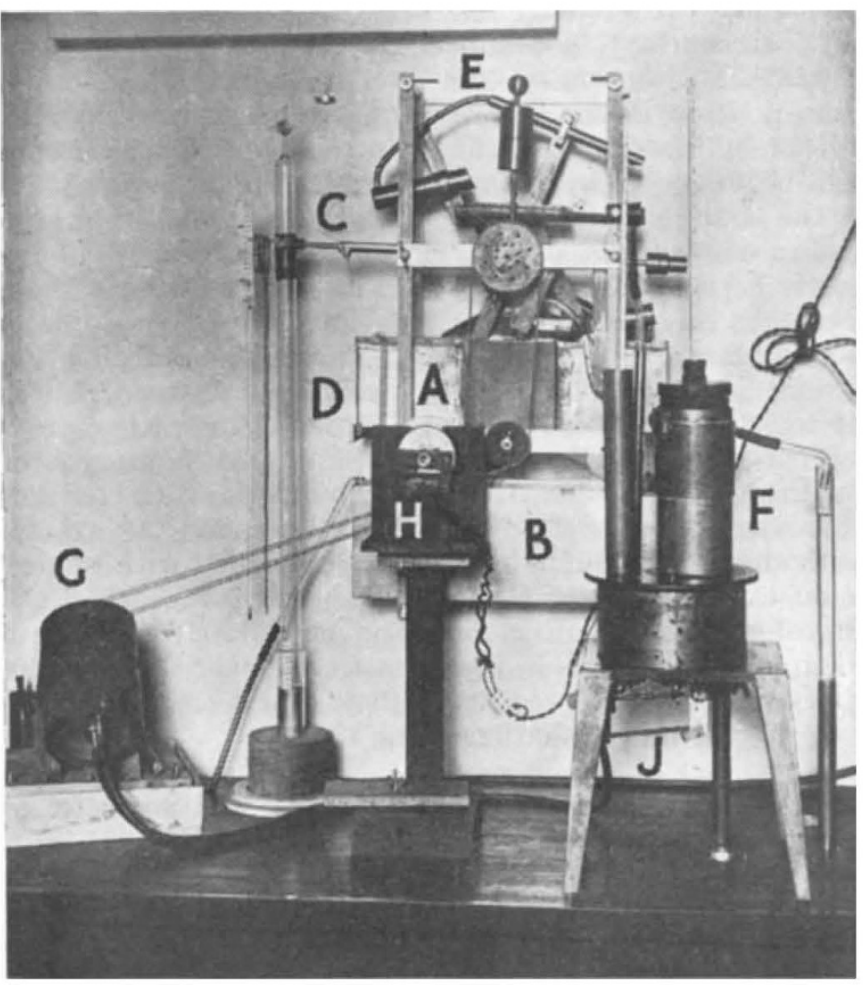

FIG. 1. Dr. Boys's new gas calorimeter. owing to its passage and is re-circulated. The rise of temperature of the water is a measure of the calorific value of the gas supply and can be observed by thermometers inserted respectively in the inlet and outlet water, or can be recorded by thermometers, preferably of the electrical type, connected with an electric recorder.

Concluding his remarks, Dr. Boys stated that he had carried out the whole of the work single-handed and had constructed the whole of the apparatus himself. "For sixty years the Gas Referees have been men of high scientific distinction. My predecessors were Sir Arthur Rücker and Prof. Tyndall and my colleagues and their predecessors were of equal standing. This has always been considered necessary because of the technical difficulties of the questions which they had to decide. The Gas Referees have been in the position of judges, between the gas maker and the gas consumer. Though provision for appeal on their decisions is available, no appeal in all that time has ever been made and heard. Now the Board of Trade is knocking at the for supplying gas and oxygen to the burner, if desired. The constructional materials used in the calorimeter comprise ordinary glass for the combustion chamber, a Pyrex glass burner tube and brass and German silver, the latter being protected by a coating of special bakelite varnish which very effectually prevents corrosion of the base metal by the products of combustion. The water flowing through the calorimeter suffers no deterioration door of Parliament to replace the Gas Referees by the cumbersome machinery of the Civil Service."

Dr. Charles Carpenter, president of the South Metropolitan Gas Co., expressed his very high appreciation of the work done for the gas industry by the Gas Referees, and stated that he was unable to understand how the Government is being so misguided as to recommend the abolition of these posts.
J. S. G. T.

\section{Obituary}

Prof. A. B. Macallum, F.R.s.

$\mathrm{P}$ ROF. A. B. MACALLUM, who died on April 5 at London, Ontario, in his seventy-sixth year, may be regarded as the pioneer of general physiology in Canada. Educated at the University of Toronto, he received his training in physiology under Newell Martin in the then newly organised Johns Hopkins University. Returning to his alma mater in 1887, as lecturer in physiology on the staff of biology under Ramsay Wright, he devoted himself to investigations bearing on the interpretation of microchemical reactions.

Macallum's first paper, on the demonstration of iron in chromatin, was published in 1891 (Proc. Roy. Soc., 50, 277) and it was followed two years later by a second one (J.Physiol., 26, 268 ; 1893) dealing with the path of absorption of this element from the alimentary canal. Methods were then 